REVISTA DE DERECHO UNED, NÚM. 11, 2012

\title{
EL MODELO CONFEDERAL E IMPERFECTO DE PROTECCIÓN DE DERECHOS FUNDAMENTALES EN LA UE ${ }^{1}$
}

\author{
THE CONFEDERAL AND IMPERFECT MODEL \\ OF FUNDAMENTAL RIGHTS PROTECTION IN EU
}

\author{
MANUEL FONDEVILA MARÓN \\ Investigador Universidade da Coruña
}

Resumen: El presente trabajo sostiene que el sistema confederal de protección de Derechos Fundamentales de la Unión Europea es imperfecto, pues aunque la Carta de Derechos Fundamentales tiene, desde la entrada en vigor del Tratado de Lisboa, pleno valor jurídico, no está reconocido un procedimiento de amparo específico para la protección de los Derechos Fundamentales que contiene. Además, el diseño institucional de la Unión Europea no permite que la Carta pueda invocarse, como ocurre en otros sistemas federales de protección de Derechos Fundamentales tales como Estados Unidos o Alemania, cuando el derecho se pretende hacer valer en un supuesto de aplicación del Ordenamiento Jurídico estatal.

Palabras clave: Unión Europea; Derechos Fundamentales; Competencias.

Abstract: This paper argues that the confederal system of protection of fundamental rights of the European Union is deficient. Although the Chapter of Fundamental Rights has, since the entry into force of Lisbon Treaty, full legal value, is noticed that it is not

${ }^{1}$ El presente trabajo es una versión, ampliada y corregida, de la Comunicación presentada en el II Congreso Internacional «Sistema Multinivel y Protección de Derechos Fundamentales en Tiempo de Crisis» celebrado en Bruselas, los días 28, 29 y 30 de mayo de 2012 . 
recognized a procedure specifically for the protection of fundamental rights contained. Moreover, the institutional design of the European Union does not allow the Charter can be invoked, as in other federal systems for the protection of fundamental rights such as the U.S. or Germany, when the right is to be enforced in a case of application of the legal state.

Keywords: European Union; Fundamental Rights; Competencies. Recepción original: 11/09/2012

Aceptación original: 14/09/2012

Sumario: I. Introducción; II. Notas sobre los modelos de protección de Derechos Fundamentales en los sistemas federales comparados; III. El imperfecto sistema de protección de Derechos Fundamentales en la UE; IV. La protección de los Derechos Fundamentales en relación con el reparto de competencias entre la Unión y los Estados Miembros.

\section{INTRODUCCIÓN}

La tesis que vamos a sostener es que la Unión Europea cuenta, tras la entrada en vigor del Tratado de Lisboa, con un sistema (con)federal de protección de Derechos Fundamentales, y que éste resulta imperfecto. En los epígrafes que siguen vamos a ver cómo se protegen los Derechos Fundamentales en la Unión Europea en comparación con otros sistemas federales. Pero, para ello, es necesaria una breve introducción sobre qué consideramos una Confederación de Estados y en concreto, un sistema (con)federal de protección de Derechos Fundamentales.

La Unión Europea, tal y como nosotros la concebimos, de ningún modo puede ser caracterizada mejor que describiéndola, en palabras del Profesor A. La Pérgola, como una «Confederación de Estados en sentido moderno», es decir, como una Confederación de Estados cuya principal novedad es que tiene como sujetos destinatarios no sólo a los Estados, sino a los ciudadanos ${ }^{2}$. Siendo así, es lógico que el Tribunal de Justicia aceptase, como veremos después, incluso antes de que la Unión Europea tuviese competencia específica en materia de Derechos Fundamentales, que el ordenamiento jurídico comunitario tenía que reconocer y proteger los Derechos Fundamentales de

\footnotetext{
${ }^{2}$ Cfr., LA PÉRGOLA, A. «Sguardo sul federalismo e i suoi dintorni (una célebre dicotomía: «stato federale-confederazione», La Confederazione di tipo antico e moderno. L'idea europeistica di comunità). En Diritto e Societá. 1992 (3). Pág. 503.
} 
los ciudadanos en su ejecución y desarrollo. Y es que en buena medida, como explica el Profesor A. Cantaro, la legitimidad que la Unión Europea ha intentado arrogarse es una legitimidad "por los derechos», o lo que es lo mismo, una legitimidad consecuencia de haber contribuido a mejorar sustancialmente las condiciones de vida de los ciudadanos $^{3}$. Lo que ocurre es que, como decimos, la construcción de un sistema de protección de Derechos Fundamentales en la Unión Europea es una tarea, al menos en parte, todavía pendiente.

Para contrastar esta afirmación es menester considerar los elementos caracterizadores de un sistema federal de protección de Derechos Fundamentales. Según el Profesor J.C. Gavara de Cara un sistema de protección federal de los Derechos Fundamentales debe constar: a) de un catálogo de Derechos de carácter constitucional en ese nivel de gobierno; b) un Tribunal Constitucional también para ese nivel; c) un recurso de amparo, ejercitable por los ciudadanos, para la protección de los Derechos Fundamentales garantizados en ese ámbito ${ }^{4}$.

A nuestro juicio, estos elementos caracterizan tanto un sistema multinivel de protección de Derechos en un Estado Federal como en una Confederación de Estados pues ambos tipos de organización no se distinguen en este aspecto (incluso, los tres elementos que hemos mencionados son aplicables también, con pequeños matices, como el hecho de que el tribunal no lo es de justicia «constitucional», a Organizaciones Internacionales de Protección de Derechos Fundamentales como el Consejo de Europa), sino, fundamentalmente, por la regla de la unanimidad que rige, en la Confederación de Estados, para la aprobación de acuerdos fundamentales, lo cual no es sino consecuencia, de que en este tipo de forma política, la soberanía sigue perteneciendo a cada uno de los Estados. A mayor abundamiento, no se podrá negar que existe una lógica similar en la Unión Europea y en los Estados compuestos que la integran cuando, limitándonos únicamente al caso de España, y como ha señalado el Profesor R. Canosa, disposiciones contenidas por ejemplo en los artículos 37.4 del Estatuto catalán (introducido además, durante su tramitación en el Congreso de los Diputados), 13.3 del balear, 13 del andaluz, 6.3 del aragonés idénticos al artículo 51.2 de la Carta de

${ }^{3}$ Cfr. CÁNTARO, A. Europa Soberana, la Constitución de la Unión entre guerra y derechos. El viejo topo, Barcelona, 2006. Págs. 107 y ss. J. A. Portero lo llama «legitimidad por eficacia» PORTERO MOLINA, J. A. «Legitimidad democrática y Constitución Europea». Revista de Derecho Constitucional Europeo, n. ${ }^{\circ} 3$, 2005. Págs. 18 y ss.

${ }^{4}$ Cfr., GAVARA DE CARA, J.C «Los Derechos Fundamentales en las Constituciones de los Länder». GAVARA DE CARA, J.C (ed) Los Derechos como principios objetivos en los Estados compuestos. Bosch. Barcelona 2010. Pag. 161. 
Niza respecto a que los derechos enumerados no alteran el reparto competencial entre el Estado y la Comunidad Autónoma o la Unión Europea respectivamente ${ }^{5}$.

\section{NOTAS SOBRE LOS MODELOS DE PROTECCIÓN DE DERE- CHOS FUNDAMENTALES EN LOS SISTEMAS FEDERALES COMPARADOS}

Lo que caracteriza a los sistemas federales (utilizado aquí este término en sentido amplio para referirnos tanto a Estados Federales como a Confederaciones de Estados) es, por tanto, la existencia de una división horizontal de competencias en dos ámbitos delimitados de poder que, y esta es la problemática esencial subyacente, si han de reputarse democráticos, habrán de ser respetar y garantizar los Derechos Fundamentales en su desarrollo y ejecución. Por eso se diferencian, huelga decir, de Organizaciones Internacionales de Protección de Derechos Humanos como el Consejo de Europa al que nos hemos referido en el apartado anterior, que si bien cuentan con un catálogo de derechos, un tribunal de justicia, y un procedimiento de protección de tales derechos, no existe, propiamente, un nivel de gobierno ni un ordenamiento jurídico vinculante propio del mismo, excepto, obviamente, el catálogo de derechos mismo.

Al objeto de estas páginas no nos interesa demasiado constatar el hecho de que existen tanto en el continente europeo (Austria, España, Italia) como en el americano (México), sistemas federales de protección de Derechos Fundamentales «imperfectos» desde la perspectiva que hemos esbozado, por faltar alguno de los elementos definidores, como constatar que esto es así particularmente en la Unión Europea a diferencia de en los otros dos modelos «perfectos» como son Alemania o Estados Unidos. Modelos, por lo tanto, en parte similares pero, como veremos a continuación, en parte diferentes.

Refiriéndonos a Alemania, hay que advertir, respecto del primero de los elementos (la existencia de catálogos de Derechos) que si evidentemente existe un catálogo de derechos a nivel federal directamente aplicables en todo el territorio, sólo diez de los dieciséis estados miembros han adoptado catálogos de derechos en sus constituciones estatales. No obstante, esto lo hacen, obviamente, en el libre ejercicio de su autonomía política y lo verdaderamente importante

${ }^{5}$ Cfr. CANOSA USERA, R. «Las Declaraciones de Derechos en los nuevos Estatutos de Autonomía». Teoría y Realidad Constitucional. $n .^{\circ} 20$ (2008) pág. 69. 
es que, todos ellos tienen la posibilidad constitucional de proclamarlos. Los Estados cuentan con su propio Tribunal Constitucional y existe también el Tribunal Constitucional Federal con jurisdicción en todo el territorio. Los Estados, por su parte, que tienen un catálogo de derechos propios tienen también, excepto Bremen, un procedimiento de amparo ejercitable por los ciudadanos frente a su Tribunal Constitucional estatal.

Pero al margen de estas cuestiones obvias para cualquier jurista informado, el modelo alemán se asemeja al estadounidense también en que se articula como un sistema alternativo de protección de Derechos Fundamentales, lo cuál quiere decir que los litigantes pueden optar, en caso de duplicidad de derechos en la Constitución federal y estatal, por el procedimiento de amparo ante los tribunales que deseen ${ }^{6}$. Existe, sin embargo, una diferencia esencial respecto del modelo de protección federal de Derechos Fundamentales estadounidense (cuyo repaso de elementos definidores ahorramos, por ocioso, al lector) pues allí es posible que, supuesta la duplicidad de un mismo derecho declarado en términos similares tanto en la Constitución federal como en la constitución estatal, los tribunales supremos estatales le otorguen un contenido distinto al del Tribunal Supremo federal, dado que están interpretando «un documento distinto, con una historia propia, y su singularidad puede justificar una decisión diferente» y sus sentencias a este respecto son firmes, puesto que, de acuerdo con la doctrina legal de los «fundamentos estatales adecuados e independientes» las sentencias basadas únicamente en la ley estatal no son revisables por los tribunales federales ${ }^{7}$. En Estados Unidos, por lo tanto, en este supuesto de duplicidad el abogado litigante escogerá, probablemente, uno u otro procedimiento ante uno u otro tribunal de acuerdo con sus intereses y perspectivas respecto al resultado del juicio, que como decimos puede ser diferente, mientras que ello resulta impensable en los Alemania, donde, por imperativo del artículo 142 LF, Bonn los derechos consagrados en los Länder no pueden entrar en contradicción con los reconocidos a nivel federal, lo que supone la pérdida de aplicabilidad de aquellos respecto de éstos cuando se declare su contradicción ${ }^{8}$.

En el seno de la Unión Europea ni una ni otra opción parecen jurídicamente satisfactorias. La solución del modelo alemán no lo

${ }^{6}$ Cfr. GAVARA DE CARA, J. C. óp. cit. pág. 181.

${ }^{7}$ Cfr., TARR, A. «Federalismo y la Protección de los Derechos en los Estados Unidos» en APARICIO, M. A. (ed) Derechos y Libertades en los Estados Compuestos. Atelier. Barcelona 2005. pág. 59.

${ }^{8}$ Cfr. GAVARA DE CARA, J. C. óp. cit. pág. 174. 
es porque no existe, hasta donde a nosotros se nos alcanza, una disposición similar a la del artículo 142 LF en los Tratados. Ello implicaría que el Tribunal de Justicia tendría la facultad de revisar las sentencias de los tribunales nacionales en aplicación del Derecho nacional lo que, en modo alguno, puede deducirse de los Tratados. Tampoco la solución del modelo norteamericano es posible, pues en Europa no existe una doctrina como la que hace referencia el Profesor A. Tarr, sino que, al contrario, desde el caso Simmenthal y en aplicación del principio de primacía afirmado en el caso Costa c/ Enelel Tribunal de Justicia sentó el principio de que no era posible alegar cuestiones de carácter constitucional (por ejemplo, la inconstitucionalidad declarada por el Tribunal Constitucional de una norma) como excusa para no aplicar de forma homogénea en todos los Estados el Derecho Comunitario.

\section{EL IMPERFECTO SISTEMA DE PROTECCIÓN DE DERECHOS FUNDAMENTALES EN LA UE}

La protección de los Derechos Fundamentales en Europa ha atravesado por varias etapas. Con anterioridad a 1969, el Tribunal de Justicia de las Comunidades Europeas evitaba hacer consideraciones acerca de los Derechos Fundamentales por considerar que quedaban fuera del ámbito comunitario. A partir de esta fecha se produce un «giro copernicano» en la jurisprudencia del Tribunal ${ }^{9}$ que partir de entonces reconoce que: 1) «los Derechos Fundamentales de la persona están comprendidos dentro de los principios generales del derecho comunitario cuyo respeto garantiza el Tribunal de Justicia ${ }^{10}$. 2) Que la protección de estos Derechos Humanos está inspirada en las tradiciones constitucionales de los Estados miembros ${ }^{11}$. 3) Junto con las tradiciones constitucionales de los Estados miembros, los principios generales pueden ser también deducidos de los textos internacionales y especialmente del Convenio Europeo de Derechos Humanos ${ }^{12}$. A partir de este momento, la protección de los Derechos Humanos en el ámbito comunitario fue construida casuísticamente por el TJCE, que fue reconociendo en distintas sentencias derechos tales como la

${ }^{9}$ Cfr. CARRILlo SALCEDO, J. A. El Convenio Europeo de Derechos Humanos. Editorial Tecnos, Madrid, 2003. Págs. 114 y ss.

${ }^{10}$ Vid. STJCE de 12 de noviembre de 1969 (casoStandder).

${ }^{11}$ Cfr. CARRILLO SALCEDO, JA. op cit. pág. 114. Vid. también STJCE caso InternationaleHandelsgesellschaft, de 1970.

${ }^{12}$ Idem y también Vid. STJCE de 14 de Mayo de 1974 (caso Nold). 
propiedad, libre ejercicio de una actividad económica, reagrupación familiar, derecho de defensa, libertad religiosa etc. ${ }^{13}$

Desde que en 1979 en un memorándum de la Comisión al Consejo se propusiera la incorporación de la UE, como organización internacional, al Convenio Europeo de Derechos Humanos ${ }^{14}$, esta ha sido una necesidad que se ha venido exponiendo de forma recurrente por actores y teorizadores de la UE. El Consejo de Ministros solicitó en 1995 al TJCE que emitiera un dictamen acerca de la posibilidad de adherirse al Convenio de Roma, y en su Dictamen 1/1996, de 28 de Marzo, el TJCE respondió negativamente, afirmando que la UE no tenía competencia, atribuida en los Tratados, en materia de Derechos Humanos. A la luz de la respuesta del TJCE comenzó a gestarse la idea de adoptar un catalogo propio de Derechos Humanos, que tuvo como resultado la aprobación de la Carta de Niza en 2000. La aprobación de este catalogo de Derechos Fundamentales de la Unión no implicó que se desechase la idea de incorporar a la UE como tal, y a pesar de que todos los Estados de la UE forman ya parte del Consejo de Europa, al CEDH. Además, la Carta de Derechos Fundamentales de la Unión Europea no fue incorporada a los Tratados, permaneciendo así, desde su aprobación hasta la entrada en vigor del Tratado de Lisboa como un documento de referencia sobre el que no sólo el TJCE sino algunos tribunales nacionales se han inspirado pero sin poder hablar en rigor de eficacia jurídica de la misma. Eficacia que se ve matizada por una serie de factores como son: 1) En primer lugar, el Título VII de la Carta de Derechos Fundamentales de la Unión Europea, tal como fue adaptada el 12 de Diciembre de $2007^{15}$, recoge una serie de requisitos para la aplicación de la Carta reduciendo su ámbito de aplicación únicamente a las instituciones y organismos comunitarios, dentro del respeto al principio de subsidiariedad y a las de los Estados Miembros en aplicación del Derecho Comunitario (art. 51.1). 2) Establece, además, y aunque resulta innecesario a tenor de lo anterior, que ninguna de las disposiciones de esa Carta altera el reparto de competencias entre los Estados y la Unión. 3) Incluso y en lo que respecta únicamente a la aplicación del Derecho Comunitario por parte de los órganos estatales, la Carta de Derechos de la Unión Europea no es de aplicación todos los países de la Unión, en virtud del Protocolo $n^{\circ} 30$ sobre la aplicación de la Carta de los Derechos Fundamentales de la Unión Europea a Polonia y Reino Unido y que establece, en su artículo 1.2 que la Carta no crea ningún derecho que se pueda ejercitar delante de

\footnotetext{
${ }^{13}$ Idem.

${ }^{14}$ Ibidem. pág. 123.

${ }^{15}$ Vid. DOUE 30.3.2010.
} 
los Tribunales de estos países, excepto aquellos que coincida con derechos reconocidos por sus respectivas legislaciones nacionales. De todo ello se concluye, que la Carta de Derechos Fundamentales de la Unión Europea sigue a ser, si la comparamos con el CEDH, un instrumento de defensa muy inferior, y si bien el artículo 6.1 TUE permite ahora que la Unión se adhiera a dicho convenio, el cambio tampoco resulta sustancial por cuanto que cada uno de los Estados Miembros de la misma ya eran signatarios del Tratado de Roma de 1950.

En cualquier caso, lo que nos muestra este excursuses, y de acuerdo con el esquema de análisis que hemos trazado, que existe actualmente en la Unión Europea un catálogo de Derechos Fundamentales con, en principio, fuerza jurídica vinculante. Si analizamos ahora el segundo de los elementos que mencionábamos de la mano del Profesor J.C Gavara de Cara, es indudable que la Unión Europea tiene también un poder judicial propio encarnado por el Tribunal de Justicia de la Unión Europea ${ }^{16}$, que se configura como el máximo intérprete del Derecho Comunitario y custodio de los Tratados, en tanto que tiene competencia para cotejar que el Derecho derivado se ajusta al Derecho originario.

Lo que ocurre, sin embargo, -y por lo que respecta tercer elemento- es que el Tribunal de Justicia no tiene competencia en materia de protección de Derechos Fundamentales, o dicho de otro modo, no existe a nivel europeo ninguna suerte de procedimiento de amparo frente a presuntas vulneraciones de los Derechos Fundamentales consagrados en la Carta de Niza de $2000^{17}$. El Tratado de Lisboa mejora las posibilidades de impugnación de actos comunitarios por parte de los particulares, pero sin poner en sus manos un procedimiento específico de protección de derechos contra actos de aplicación del Derecho Comunitario.

Es por esto último por lo que nos referimos a la Unión Europea como un modelo «imperfecto». Caracterización de naturaleza puramente teórica que, sin embargo, tiene también consecuencias de

${ }^{16}$ Vid. arts. 251 y ss. del TFUE y MANGAS MARTÍN Y NOGUEIRAS, J. Instituciones y Derecho de la Unión Europea, Editorial Técnos, Madrid. 2004. Págs. 205 y ss.

${ }^{17}$ Cfr., en este sentido, BLASI CASAGRÁN, C. "La protección de los Derechos Fundamentales en el Tratado de Lisboa» en Quaderns de Treball del Institut Universitari D'Estudis Europeus. N. ${ }^{\circ} 51$ de octubre 2010, publicado en internet. La autora, explica como el Tratado de Lisboa aumenta las posibilidades jurídicas de las personas físicas para impugnar actos reglamentarios (que incluyen los actos legislativos) que les afecten, pero únicamente lo podrán hacer ante el juez nacional de su Estado, y si este se niega a elevar la cuestión al TJUE, el particular se verá sin posibilidades de mantener ante este órgano su pretensión (pág. 48). 
carácter práctico. La principal, y al hilo de nuestro discurso, es que a falta de este procedimiento de amparo propio, la responsabilidad de protección de los Derechos Fundamentales de la Unión Europea recae en los tribunales nacionales, con la limitación evidentemente de no poder anular por si mismos actos o disposiciones provenientes de las instituciones de la Unión. Y el corolario, también de carácter práctico, que se deduce de todo lo expuesto, en el caso de posible duplicidad de derechos en las Constituciones de los Estados miembros y en la Carta de Niza, es, a nuestro juicio, que los tribunales nacionales (incluidos, en su caso, Tribunales Constitucionales), cuando el recurso de amparo se invoque respecto de actos o disposiciones cuya materia esté comprendida dentro de las competencias de la Unión estarán obligados por la interpretación que, en su caso, haga el Tribunal de Justicia o, si se pensara que existe alguna laguna, a plantear la cuestión prejudicial, mientras que la interpretación que los Tribunales Constitucionales, en tanto que garantes de los Derechos Fundamentales declarados en la Constitución, será la única vinculante en caso de amparos planteados frente actos y disposiciones derivadas del Derecho puramente nacional.

Postura, que nos parece la única compatible con el art. 51.1 de la Carta de Niza, y con la doctrina del juez nacional como juez comunitario y que, aunque ocioso debiera ser mencionarlo, en ningún caso implica cesión de soberanía por parte de los Estados ni mucho menos una pérdida de autoridad por los Tribunales Supremos y Constitucionales de los Estados, pues aplicar las normas de Derecho Comunitario (en la interpretación otorgada por su máximo intérprete) dentro de los ámbitos de su competencia, es, una exigencia del propio Derecho Constitucional (en nuestro caso, derivada del art. $93 \mathrm{CE}$ ).

\section{LA PROTECCIÓN DE LOS DERECHOS FUNDAMENTALES EN RELACIÓN CON LA DISTRIBUCIÓN DE COMPETENCIAS ENTRE LA UNIÓN Y LOS ESTADOS MIEMBROS}

El artículo 51 de la Carta de Derechos Fundamentales, ha de ponerse en relación con los ya mencionados nuevos artículos 5.2 TUE, del cual han desaparecido las competencias implícitas, y el artículo 352 TFUE que agrava los requisitos para poder ejercitar la vis expansiva de las competencias, que requerirá la aprobación, y no la mera consulta, al Parlamento Europeo.

Del tenor literal de la carta, parece natural, extraer la conclusión a la que llega la Profesora P. Biglino: «La Carta supone la consolida- 
ción del control que el Tribunal de Justicia (y los jueces nacionales, como jueces comunitarios) ejercen sobre los órganos de la Unión y sobre los Estados miembros, siempre que estos actúen en el marco del Derecho Comunitario. Esto no significa, sin embargo, que el poder legislativo o ejecutivo de la Comunidad asuman nuevas competencias. Es cierto que dichos poderes están obligados a proteger y a promover los Derechos Fundamentales como, por lo demás, deben hacer todas las instituciones en cualquier sistema político contemporáneo. Pero al llevar a cabo esta tarea, las instituciones y órganos de la Unión tienen que esgrimir una competencia que ya posean en virtud de los Tratados. En definitiva, lo que la Carta excluye es que los Derechos Fundamentales sean un título competencial autónomo, que habilite a la Unión a dictar normas destinadas exclusivamente a garantizar su protección» ${ }^{18}$.

Sin embargo, el artículo 51 de la carta, y en concreto el vocablo «aplicación» ha provocado algunos problemas de interpretación. Uno de ellos, lo señala la Profesora de la Universidad de Valladolid y versaría sobre si la Carta de Derechos Fundamentales resulta de aplicación cuando los Estados se sujetan a una excepción de la aplicación del Derecho Comunitario. Para esta autora, quien reconoce explícitamente seguir la teoría jurídica kelseniana la respuesta es positiva, dado que, a su juicio, las excepciones a las que se sujetan, en este caso, los Estados, no son una "competencia residual» y por lo tanto «exclusiva» de estos, sino una competencia "concurrente», en tanto que la excepción ha sido prevista y permitida por el ordenamiento comunitario. En tanto que nosotros mantenemos justamente la metodología, también explícitamente expuesta, contraria, a nadie puede extrañar que discrepemos de tal postura, entendiendo, frente al monismo jurídico de esta autora, que las excepciones a la aplicación del Derecho Comunitario no son una «autorización» del Derecho Comunitario sino, como su propio nombre indica, una reserva por parte de los Estados que, tal y como nosotros concebimos al Derecho Comunitario, son el origen último del fundamento del Derecho Comunitario.

Existe un segundo aspecto problemático que suscita el término "aplicación»: En unas conclusiones publicadas recientemente, y sobre un caso que en el momento en el que escribimos estas líneas aun no está concluido, el Abogado General P. Cruz Villalon expone una tesis original, que él mismo reconoce no acorde con la jurispruden-

${ }^{18}$ BIGLINO CAMPOS, P. «Derechos Fundamentales y Competencias de la Unión: el argumento de Hamilton». En Revista de Derecho Comunitario Europeo. Año 7. ${ }^{\circ}$, n. ${ }^{\circ} 14$. pág. 66. 
cia del Tribunal de Justicia, sobre como debería entenderse esta vinculación con el Derecho Comunitario ${ }^{19}$. Aunque las circunstancias del caso no lo exigían, y esto lo reconoce expresamente el Abogado General, se sintió, sin embargo, obligado a ofrecer esta argumentación en torno al artículo 51 de la Carta, esperando que el Tribunal la haga suya a fin de ir construyendo una doctrina jurisprudencial al respecto. Es sólo en torno a esta cuestión por lo que el contenido de las conclusiones nos interesa.

Comienza afirmando que la relación entre la Unión y los Estados miembros debe comprenderse con la fórmula "verfassungsverbund» ${ }^{20}$, por lo que "la consecuencia es que la asunción por parte de la Unión de la garantía de los Derechos Fundamentales en el ejercicio de la potestad pública de los Estados en estos supuestos debe examinarse en términos de desplazamiento, en el sentido de traslación de la responsabilidad original de los Estados a la responsabilidad de la Unión, en lo que dicha garantía se refiere ${ }^{21}$. De acuerdo con ello añade que "es legítimo que, en ocasiones difícilmente precisables de antemano, cuente el interés de la Unión en dejar su impronta, su concepción del derecho fundamental, con prioridad respecto de cada uno de los Estados miembros, (...). Este especial interés encuentra su principal fundamento en la presencia o incluso el protagonismo del Derecho de la Unión en el Derecho nacional en cada caso configurado. En definitiva, se trata de supuestos en los que la legitimidad de la res pública europea puede estar en juego, y esta consideración debe encontrar adecuada respuesta ${ }^{22}$. Por todo ello, concluye, "una clausula característicamente abierta como es la que hoy se recoge en el apartado 1 del artículo 51 de la Carta necesita de una determinación básica de su sentido. Ello debe tener lugar, en primer lugar, mediante la determinación de diversas situaciones en la que el desplazamiento de la garantía de los derechos fundamentales desde los Estados hacia la Unión puede encontrarse, en línea de principio, justificado. En segundo lugar, considero, que una ponderación de las circunstancias concretas de cada caso debe permitir un juicio final y definitivo respecto de la adscripción de la responsabilidad de la garantía ya sea a la Unión, ya sea a los Estados» ${ }^{23}$.

${ }^{19}$ Vid. Conclusiones del Abogado General Pedro Cruz Villalón en el Asunto C-617/10 publicadas el 12 de junio de 2012.

${ }^{20}$ Párr. 35.

${ }^{21}$ Párr. 37. Cursiva en el original.

22 Párr. 41.

${ }^{23}$ Párr. 46. 
Su argumentación, transcrita en los aspectos que hemos considerado más relevantes en el párrafo anterior, es demasiado abstracta como para permitir juicios precipitados. En todo caso está necesitada -a nuestro juicio- de precisiones y concreciones. Lo que no podemos admitir, de ningún modo, es que haya habido un desplazamiento de la responsabilidad de protección de los Derechos Fundamentales por parte de los Estados a la Unión Europea, si quiera en algunas áreas. La responsabilidad universal de protección de los Derechos Fundamentales sigue recayendo en los Estados, aunque estos hayan decidido que cuando el conflicto tenga lugar a propósito de la aplicación del Derecho Comunitario decidan los jueces comunitarios (que son también jueces nacionales), y en última instancia el Tribunal de Justicia, de acuerdo con las disposiciones de la Carta. Sostener lo contrario no sólo no es conforme a la jurisprudencia, al menos hasta la fecha, del Tribunal de Justicia sino a la jurisprudencia de los Tribunales Constitucionales europeos, que, como veremos más adelante, aun con distintos matices, han sostenido que en ultima instancia es a ellos a los que les corresponde ser los garantes últimos de la soberanía popular, en el caso, por más que difícilmente imaginable, que la integración europea pudiera ponerla en peligro.

Haciendo un esfuerzo de concreción nosotros sostenemos: 1) que la Carta de Derechos Fundamentales, en la interpretación que le dé su máximo intérprete (el Tribunal de Justicia) es jurídicamente vinculante para el juez nacional, y el único catálogo de referencia, cuando se trate de ejecutar los actos legislativos comunitarios que tienen eficacia directa. En estos casos, el único catálogo de derechos de referencia para el juez nacional (que es juez comunitario) es la Carta. Es más, en el caso de posible duplicidad de derechos en las Constituciones de los Estados miembros y en la Carta de Niza, los jueces estarán vinculados a la interpretación que de dicho precepto haya hecho, el Tribunal de Justicia. Es menester hacer notar que aquí, el juez nacional incluye también al Tribunal Constitucional, que apartándose aparentemente de su anterior jurisprudencia ${ }^{24}$ admitió recientemente elevar una cuestión prejudicial al Tribunal de Justicia, preguntando a este órgano la interpretación, que de acuerdo con la Carta de Derechos Fundamentales, debía darse a

${ }^{24}$ Vid., por ejemplo, STC 28/1991. En realidad, esta Sentencia y el Auto citado infra no son absolutamente incompatibles. No ha dicho, el Tribunal Constitucional, en este Auto, que el Derecho Comunitario forme parte del bloque de Constitucionalidad o pueda servir para enjuiciar la constitucionalidad de una norma. Ha dicho, en síntesis (Fdtojco 4, apartados «b» «c») que el incorrecto conocimiento del juez nacional del Derecho Comunitario puede vulnerar el Derecho Constitucional a la tutela judicial efectiva. 
una determinada Decisión Marco de la Unión Europea ${ }^{25}$. 2) En el caso de normas nacionales en trasposición de las directivas de la Unión Europea, tampoco puede haber duda de que la solución es la misma que en el caso anterior por cuanto la norma nacional recoge exactamente las disposiciones de la directiva, pues el control que pueden hacer los órganos comunitarios se basa en los mismos fundamentos que cuando se sostiene el incumplimiento del Derecho Comunitario por una trasposición defectuosa. La quaestio disputata surge únicamente, en el marco de apreciación del Estado nacional. La argumentación del Profesor y Abogado General P. Cruz parece dirigida a sostener, en definitiva, que también aquí la Carta de Derechos Fundamentales entra en juego, y con ella, la competencia del TJUE. Desde nuestra concepción dualista del Derecho, a nadie puede extrañar que, por entender nosotros que el ámbito de aplicación nacional es Derecho estatal, y no Comunitario, la solución deba ser la misma que en el caso de aplicación pura y simple de una norma nacional. No creemos que se pueda sostener, en rigor, ningún «interés legítimo», por utilizar las palabras del Abogado General, como categoría jurídica, de la Unión, en el margen de apreciación del Estado nacional. 3) En el caso de no encontrarnos ante un supuesto de aplicación del Derecho Comunitario, es obvio, la Carta no se proyecta sobre el Derecho nacional. No se proyecta, como decimos, de modo directo, pero sí como parámetro de interpretación de los Derechos Fundamentales que estén reconocidos en la Constitución, en nuestro caso, por imperativo del artículo $10.2 \mathrm{CE}$ una vez que, con la entrada en vigor del Tratado de Lisboa, la Carta de Derechos Fundamentales, es un Tratado Internacional más. Es decir, aunque no podrá ser directamente invocada por los litigantes de un proceso, ni utilizada de modo directo por el juzgador para la resolución del conflicto, en tanto que es una declaración de derechos más moderna, y por lo tanto, más conectada con la realidad social actual servirá para complementar el contenido de derechos constitucionales que puedan tener, de ser el caso, una redacción algo menos precisa ${ }^{26}$. Por ejemplo: el artículo 15 de la Constitución Española, puede ver complementado su contenido, en un litigio concreto, con el artículo 3.2 CDFUE. Los derechos sociales, aunque en nuestra Constitución estén expresamente excluidos del procedimiento de amparo (art. 53

${ }^{25}$ Vid., ATC 86/2011. Y para un comentario completo ARROYO JIMENEZ, L. «Sobre la primera cuestión prejudicial planteada por el Tribunal Constitucional: bases, contenido y consecuencias» en Indret. N. ${ }^{\circ} 4$ (2011).

${ }^{26}$ Vid., MARÍN AÍS, R. «La Carta de Derechos Fundamentales de la Unión Europea en España con el Tratado de Lisboa». En Revista Digital de la Facultad de Derecho UNED. N. 2 (Monográfico Premios García Goyena) (2010). Págs. 8 y ss. 
CE) y aunque el paradigma dominante del positivismo jurídico los sigue considerando meras normas programáticas, a pesar de lo que se podía deducir de la propia estructura de la Carta, también pueden verse favorecidos, aun cuando nos movamos en el ámbito competencial puramente interno, por las disposiciones de la Carta. En primer lugar porque la Constitución, como norma jurídica, vincula a todos los poderes públicos y no sólo a los tribunales de justicia, por lo que si atendemos al artículo $41 \mathrm{CE}$, en relación con el artículo 34 CDFUE, podemos interpretar el primero (derecho a la seguridad social) al amparo del segundo en el sentido de que la seguridad social deberá ofrecer, al menos, las prestaciones que en este se contienen. En segundo lugar, en caso de que los poderes públicos incumplan su obligación de mantener un sistema de aseguración público que contenga al menos las prestaciones del art. 34 CDFUE, podrán, los órganos legitimados para ello interponer recurso de inconstitucionalidad, con base, lógicamente, en el artículo $41 \mathrm{CE}$, pero interpretado conforme al 34 CDFUE.

La tesis aquí expuesta es la única, a nuestro juicio, viable, teniendo en cuenta, por un lado, los principios de primacía y eficacia directa del derecho comunitario, y del otro, el principio de distribución de competencias del art. 51.2. Ahora bien, debemos reconocer que se enfrenta a una dificultad. En tanto que como hemos dicho no existe un procedimiento de amparo (indirecto) ${ }^{27}$ que los ciudadanos puedan ejercitar frente actos de las instituciones nacionales o comunitarias en aplicación del Derecho de la Unión, y por más que, en algún caso, la cuestión prejudicial pueda servir a tal fin, no es el procedimiento ideal para la protección de Derechos Fundamentales (razón por la cual existe en los ordenamientos constitucionales nacionales ambos) ¿Puede plantearse un recurso de amparo por violación del Derecho Comunitario de los Derechos recogidos en la Constitución? A nuestro juicio la respuesta es un sí, pero con importantes matices. La dualidad del ordenamiento constitucional y comunitario debería implicar una respuesta negativa, en el sentido de que no es una cuestión «constitucional» la aplicación del Derecho Comunitario, ni una cuestión «comunitaria» (que se pueda alegar frente al Tribunal de Justicia) la posible violación de un derecho reconocido en la Constitución. Sin embargo es imposible ignorar, de un lado, que existe una conexión última entre ambos órdenes que no puede ser ignorada, como ha reconocido nuestro Tribunal Constitucional a

${ }^{27}$ La posibilidad de que un ciudadano interponga recurso de anulación (art. 263 TFUE) debe ser considerado amparo directo. 
partir de la STC 58/2004, y de otro lado, el principio de soberanía popular, que implica, entre otras cosas, que no tenga lugar una merma de los derechos de la ciudadanía como consecuencia del proceso de integración. Por eso a nuestro juicio es razonable y prudente, la solución intermedia sostenida por el Tribunal Constitucional Federal alemán en la Sentencia conocida como Caso Bananas $^{28}$. En ella el Tribunal afirma que los recursos de amparo y las cuestiones de inconstitucionalidad de Tribunales que aleguen una lesión de los Derechos Fundamentales de la Constitución por parte del Derecho Comunitario no son admisibles $a b$ initio cuando su fundamentación no evidencia que la evolución jurídica europea, incluyendo la jurisprudencia del Tribunal de Justicia de las Comunidades Europeas tras la publicación de la Sentencia Solange II haya reforzado el estándar necesario de protección de los Derechos Fundamentales. Por ese motivo, el amparo y la cuestión deben evidenciar que la protección de los derechos que se considera indispensable no se garantiza con carácter general, lo que exige una contraposición de ambos ordenamientos jurídicos. De esa contraposición debe resultar un «déficit estructural» en la protección de derechos. Este déficit estructural es más fácil que se de si, como denunciamos, no existe un proceso asimilable al procedimiento de amparo en el Derecho Procesal europeo. Nuestro Tribunal Constitucional, en la STC 58/2004, también ha reconocido la posibilidad de un amparo impugnando la aplicación por parte de los poderes públicos del Derecho Comunitario en estos términos: es claro también que, en la medida en que se impugne en amparo un acto del poder público que, habiendo sido dictado en ejecución del Derecho Comunitario europeo, pudiera lesionar un Derecho Fundamental, el conocimiento de tal pretensión corresponde a esta jurisdicción constitucional con independencia de si aquel acto es o no regular desde la estricta perspectiva del ordenamiento comunitario europeo y sin perjuicio del valor que éste tenga a los efectos de lo dispuesto en el art. 10.2 CE» y aunque los mismos puedan parecer más amplios que los del Tribunal Constitucional Federal alemán, en caso de producirse un conflicto en la actualidad, deberían matizarse consecuencia de la «objetivación» del amparo operada por la L.O. 6/200729, lo que en nuestra opinión, daría lugar a un resultado similar. Además, y aunque no

${ }^{28}$ Vid., Resolución de 7 de junio de 2000.

${ }^{29}$ Ello se ha llevado a cabo, a través del requisito de especial trascendencia constitucional por el cual, y como indica la doctrina, el TC deja prestar una tutela subjetiva de los Derechos Fundamentales de los individuos, que pasa a ser responsabilidad de la jurisdicción ordinaria, y sólo excepcionalmente, al Tribunal Constitucional. (Cfr., 
se hubiese producido esta reforma, el Tribunal Constitucional debería ser, a la hora de examinar el concreto caso de amparo que denunciase una aplicación del Derecho Comunitario contraria a los Derechos Fundamentales consagrados en la Constitución, consecuente con lo expresado en la DTC 1/2004 (posterior a esta sentencia) sobre primacía del Derecho Comunitario y Derechos Fundamentales de la Constitución. Y ello, porque como allí se dijo, hoy en día, con todo, esta posibilidad es poco más que una hipótesis remota. Además, téngase en cuenta, que cuando el TCF dictó esta Resolución, en 2000, y cuando el nuestro se pronuncio en 2004, la Carta de Derechos Fundamentales no tenía carácter vinculante, y por lo tanto, no había, en el marco de la Unión, sistema alguno de protección de derechos como tal.

por todos, Cfr., ARAGÓN REYES, M. «La Reforma de la Ley Orgánica del Tribunal Constitucional» en Revista Española de Derecho Constitucional. N. 85 (2009). Pág. 40). 